\title{
Konut ve Çevresi Kavramına Yaşam Kalitesi Bağlamındaki Yaklaşımların Değerlendirilmesi*
}

\author{
Betül Hatipoğlu Şahin ${ }^{1}$ \\ ORCID: 000-0002-0516-7120
}

*

\author{
Ayşegül Tereci ${ }^{2}$ \\ ORCID: 0000-0001-5989-9565
}

Öz

İnsanlar ve yaşadıkları çeoreyi değerlendiren yaşam kalitesi kavramının kökeni çok eskilere dayanmasına rağmen yapılan araştırmalar öncelikli olarak kavramın uzlaşılan net bir tanımının olmadığını ortaya koymaktadır. Birçok kaynakta yaşam doyumu, genel refah, yaşam memnuniyeti olarak ifade edilen kavramin, farklı kaynaklarda 100'den fazla tanımı kaydedilmiştir. Yaşam kalitesi araştırmalarl; bireylerin refah hissini oluşturan etmenlerin nedenlerini araştırma ve etkilerini ortaya koyma, memnuniyet ve memnuniyetsizliğin toplumsal ve mekânsal dağılımına iliş̧in bilgi sağlama, araştırma sonuçlarına bağgl etkin politikalar ortaya koyup bu politikalarn mekânsal etkilerini takip etme gibi amaçlar taşımaktadır. Tanımlar dışında özellikle farklı ülkelerde ve birçok akademik çalı̧̧ada yaşam kalitesi ölçümleri için farkl göstergelerin kullanıldı̆̆ı görülmektedir. Bu noktada yaşam kalitesi araştırmalarında, kişinin yaşam kalitesinin sosyal çeore ve fiziksel çevre olmak üzere iki temel faktöre bă̆ll olduğunu ortaya çıkmıştır. Özellikle bireyin mekân ve çevresiyle olan ilişkisi, araştırmalarn temel noktasın oluşturmuştur. Bu çalış̧ma kapsamında yapılan literatür araştırmasılyla konut ve çevresi için kullanicıların memnuniyet düzeylerini ve buna bağhl olarak yaşam kalitesi ölçme amacı taşıyan modeller irdelenmiştir.

Anahtar Kelimeler: yaşam kalitesi, konut, memnuniyet.

\footnotetext{
* Bu makale çalışması “5. Kent Araştırmaları Kongresi”nde bildiri olarak sunulmuştur.

1 Öğr. Gör., KTO Karatay Üniversitesi, E-mail: betulhatip@gmail.com

${ }^{2}$ Dr. Öğr. Üyesi, KTO Karatay Üniversitesi, E-mail: aysegul.tereci@karatay.edu.tr

idealkent @ C Kent Araştırmaları Dergisi (Journal of Urban Studies) 


\title{
Evaluation of Approaches to the Concept of Housing and Its Environment in the Context of Quality of Life ${ }^{*}$
}

\author{
Betül Hatipoğlu Şahin ${ }^{3}$ \\ ORCID: 000-0002-0516-7120
}

*

\author{
Ayşegül Tereci ${ }^{4}$ \\ ORCID: 0000-0001-5989-9565
}

\begin{abstract}
Although the origin of the concept of quality of life dates back to ancient times, researches primarily reveal that the concept does not have a agreed definition upon. More than 100 definitions of the concept, which is expressed as life satisfaction, general welfare, life satisfaction have been recorded in different sources. Quality of life Studies aim to investigate the causes and effects of the factors that make up the sense of well-being of individuals, to provide information on the social and spatial distribution of satisfaction and dissatisfaction, for establishing effective policies and to follow the spatial effects of these policies, it is seen that different indicators are used for quality of life measures, especially in different countries and in many academic studies. It has been revealed in the quality of life studies that the quality of life of the person depends on social environment and physical environment factors. The relationship of the individual with the place and its environment constituted the main point of the research. Within the scope of this study the models aiming to measure the satisfaction levels of the users for the house and its surroundings and accordingly the quality of life were conducted.
\end{abstract}

Keywords: quality of life, housing, satisfaction.

\footnotetext{
${ }^{3}$ Lecturer, KTO Karatay University, E-mail: betulhatip@gmail.com

${ }^{4}$ Assist. Prof. Dr., KTO Karatay University, E-mail: aysegul.tereci@karatay.edu.tr

idealkent @ C Kent Araştırmaları Dergisi (Journal of Urban Studies) 


\section{Giriş}

Sürdürülebilirlik yaşamın her alanında önemli bir kavram haline gelirken sürdürülebilirliğin ekonomik, sosyal ve çevresel boyutlarını temsil ettiği için yaşam kalitesi sürdürülebilirliğin en genel amacı olarak tanımlanabilinir (Boarini, Comola, Conal, Keulenaer ve Robert, 2010, s.7). Bu noktada yaşam kalitesinin ölçülebilir olması sürdürülebilirliğin ve uygulanan stratejilerin etkinliklerinin izlenebilmesini sağlamaktadır. Ölçme işleminde kullanılan göstergeler; yaşam kalitesinin anlaşılmasında, eğilimlerin belirlenmesinde ve çeşitli alt parametreler arasındaki ilişkilerin kurulmasında kullanılan yararlı araçlardır (Streimikiene, 2015, s.140). Yaşam kalitesinin ölçümü araştırmalarında kullanılan göstergeler nesnel (objektif) ve öznel (sübjektif) olarak iki grupta değerlendirilmektedir. Nesnel göstergeler; sayım sonuçları, devletlerin yapmış olduğu araştırma sonuç raporlarından oluşurken; öznel göstergeler yaşama dair bireylerin öznel değerlendirmelerini içermektedir (Evcil Türksever, 2001, s.21).

Yaşam kalitesinin kompleks bir yapısının bulunmasından dolayı; sosyal bilimler, mühendislik, fen bilimleri, sağlık bilimleri alanlarının araştırma konusu haline gelmiştir ve bu nedenle yaşam kalitesi kavramının tanımıyla ilgili net bir görüş birliği bulunmamaktadır. Ayrıca politikanın da bir boyutu olarak ele alınmıştır ve kentsel yaşam kalitesi araştırmaları kentlerdeki yer seçimi ve göç kararlarının verilmesinde yol gösterici olmuştur (Evcil Türksever, 2001, s.13). Kavram her bilim dalı tarafından farklı bir perspektifle değerlendirilerek, tanımlanmaktadır. Yaşam kalitesinin farklı alanlardaki tanımlamalarına rağmen nerdeyse tüm alanlarda göstergelerinden biri olarak "konut ve çevresinden memnuniyet" gelmektedir.

Konut ve çevresi kavramı, yaşam kalitesi bağlamında yapılan çeşitli çalışmalarla farklı boyutlarla ele alınmıştır. Bu makale kapsamında yaşam kalitesini ölçmeye yönelik modeller ve kullanılan göstergeler literatürde incelenerek, konut ve çevresi memnuniyeti alt başlığına bakış açışı değerlendirilecektir. Bu sayede bu alanda yapılan çalışmalara bir altlık oluşturulması hedeflenmiştir.

\section{Yöntem}

Yaşam kalitesi, konut ve çevresi memnuniyeti göstergesi arasındaki ilişki ortaya konulurken makaleler, tezler ve kitaplardan oluşan 150 kaynak taranarak yaşam kalitesi tanımının tarihsel gelişimi ele alındıktan sonra bu konudaki yaklaşım ve göstergelerin gelişimi izlenmiştir. Burada alt başlık olarak 
yer alan konut ve çevresi memnuniyetinin hangi model ve yaklaşımlarda işlendiği ayrıca değerlendirilmiştir.

\section{Yaşam kalitesi tanımının tarihsel gelişimi}

Bireyin refahını artırma odaklı; kendisine ve çevresine bakarak, bakış açısına referans vererek rehberlik eden bir düşünce olması ve kavramsallaştırma, ölçme, uygulama konuları için bütünleştirici bir tema olması nedeniyle yaşam kalitesi pek çok alanda çalışılan bir konudur. Yaşam kalitesi tanımlarına bakmadan önce pek çok çalışma alanının bu konuyla ilgilenme nedenlerini Schalock'un yaptığı araştırmaya göre;

- Odak noktasında bilimsel, tıbbi ve teknolojik gelişmeler olan; kişisel, ailevi, toplumsal ve sosyal refahın bu gelişmelere ek olarak karmaşık kombinasyonlar meydana getirip yaşamın iyileştirilebilmesinde rol oynayacağı inanc1,

- Toplumsal temelli hizmetler için bireyin toplumsal yaşantısından elde edilen sonuçları ölçebilmesi,

-Yükselen tüketici gücü ve hasta haklarının insan odaklı planlamayla amacına ulaşan kişisel sonuçlar elde edilmesine katkı sağlaması,

- Sosyolojik değişikliklerin ortaya çıkmasında yaşam kalitesinin öznel ve algısal yönlerinin bireysel özellikler bağlamında ortaya koyması nedeniyle çok boyutlu bir yapısı olması, şeklinde sıralanabilir (Schalock, 2004, s.204).

1937 yılından itibaren tıp alanında hastaların durumlarıyla ilgili ölçümlerde kullanılmasıyla birlikte araştırılmaya başlanan bir kavramdır. 1948 yılında WHO (Dünya Sağlık Örgütü)nün sağllı̆̆ "sadece hastalık veya sakatlığın olmaması değil, tam fiziksel, zihinsel ve sosyal refah durumu" olarak tanımlamasıyla önemli bir konu haline gelmiştir (Prutkin ve Feinstein, 2002, s.9). Toplumsal eşitsizliklerle ilgili farkındalığın $\operatorname{arttığı~2.~Dünya~Savaşı~son-~}$ rasında yaşam kalitesi ile ilgili sosyal içerikli pek çok alanda akademik çalışmaların başladığını görüyoruz. Özellikle 1960 sonrasında hastaların kendi sağlı̆̆ hakkındaki görüşlerin sistematik olarak toparlanmasıyla birlikte bu alandaki çalışmalarda gelişmeye başlamıştır (Jenkinson, 2020). Tarihi gelişimi içinde yaşam kalitesi tanımları Tablo.1' de verilmiştir. 
Tablo 1. Tarihsel Gelişimiyle Yaşam Kalitesi Tanımları

$\begin{array}{ll}\text { TANIMLANAN } & \text { YAŞAM KALİTESI TANIMI } \\ \text { ARAŞTIRMA } & \end{array}$

(Lansing ve Marans, 1969, Psikolojik, sosyolojik ve sembolik bileşenler vasitasılyla yükselen s.195) çevre kalitesi toplumun iyi olma halini ve yaşam memnuniyetini artturr.

(Perloff, 1969) Kentsel yaşam kalitesinin doğal ve yapılı çevrenin karşılıklı etkileşimiyle belirlendiği üzerinde durulmuştur.

\begin{tabular}{ll}
\hline $\begin{array}{l}\text { (Dalkey ve } \\
\text { Rourke, 1972, s.211) }\end{array}$ & $\begin{array}{l}\text { Kişinin, iyi olma, memnun ya da memnuniyetsiz olma, mutlu ya } \\
\text { da mutsuz olma hissidir }\end{array}$ \\
\hline (Harland, 1972) & $\begin{array}{l}\text { Hoş, güzel yaşam, sosyal refah sosyal koruma ve ilerleme, mül- } \\
\text { klerin toplamı, hizmetler, koşullar. }\end{array}$ \\
\hline (Campbell, 1981, s.265) & $\begin{array}{l}\text { Yaşam kalitesi yerleşim alanlarında yaşayan bireylerin algısına } \\
\text { göre değişen bir konudur. Çalışmada her bireyin farklı karakter }\end{array}$ \\
& $\begin{array}{l}\text { özelliklerinden dolayı düşüncelerinin farklı olabileceği öne sürül- } \\
\text { müştür. }\end{array}$ \\
\hline (Liu ve Hsieh, 1986, s.135) & $\begin{array}{l}\text { Aynu doğal ve yapılanmış çevrede yaşayan insanların, fiziksel ve } \\
\text { psikolojik refahının algıllanan durumsal ifadesi }\end{array}$ \\
&
\end{tabular}

(Wish, 1986, s.346)

Çevresel ve psikolojik bileşenleri barındıran bir kavram

\begin{tabular}{ll}
\hline $\begin{array}{l}\text { (Rice, Frone ve McFarlin, } \\
\text { 1992, s.160) }\end{array}$ & $\begin{array}{l}\text { Kişinin yaşam kalitesi yaşamdan duyduğu } \\
\text { memnuniyetle birlikte artar. }\end{array}$ \\
\hline $\begin{array}{l}\text { (Murdie, Rhyne ve Bates, } \\
\text { 1992) }\end{array}$ & $\begin{array}{l}\text { Ekonomik, politik ve sosyal bağlam, nicel (fiziksel çevre, konut } \\
\text { kalitesi, kamusal hizmetler) ve nitel } \\
\text { veriler (grup nitelikleri, hayat deneyimi, karşılaştırma } \\
\text { standartları) doğrultusunda bireyin algısına bağlı olarak genel } \\
\text { yaşam kalitesi ortaya çımaktadır. }\end{array}$ \\
\hline (Marsella, Levi & $\begin{array}{l}\text { Kişinin yaşamı boyunca kendi pozisyonunu, kültür ve değerler } \\
\text { sistemleri içinde algllayışı }\end{array}$ \\
\hline Ve Ekblad, 1993, s.60) & $\begin{array}{l}\text { Kişilerin içinde bulundukları kültür ve değer sistemleri } \\
\text { bağlamında, yaşamdaki amaç ve beklentileri doğrultusunda } \\
\text { hayattaki pozisyonlarına dair algıları }\end{array}$ \\
\hline (WHO, 1995) & $\begin{array}{l}\text { İnsani ve sosyal gelişmeyi etkilemekte olan sosyal, sağlık, } \\
\text { ekonomik ve çevresel koşullar arasındaki etkinin sonucu ortaya } \\
\text { çıan ürün }\end{array}$ \\
\hline (Shookner, 1997, s.3) & $\begin{array}{l}\text { Yaşam kalitesi; fiziksel sağlık durumu, işlevselliğin } \\
\text { yeterliliği, psikolojik durum, iyilik hali, sosyal ilişkiler, ekonomik } \\
\text { durum alanlarını içermektedir. }\end{array}$ \\
\hline (Becker ve & $\begin{array}{l}\text { Bireylerin kişisel olarak hissettikleri ve deneyimledikleri mekan- } \\
\text { lara ilişkin tecrübeleriyle kurdukları bağ }\end{array}$ \\
\hline Diamond, 1997, s.122) &
\end{tabular}




\begin{tabular}{ll}
\hline (Dissart ve Deller, 2000, s.136) & $\begin{array}{l}\text { Toplumu biçimlendiren objektif ve sübjektif değişkenlerin etkile- } \\
\text { rini ortaya koyan kavram }\end{array}$ \\
\hline $\begin{array}{l}\text { (De Hollander, A.E.M; RVIM, } \\
\text { 2000) }\end{array}$ & $\begin{array}{l}\text { Yaşam kalitesi, yaşamın maddi ve manevi donanımı ve sağllk, } \\
\text { yaşam ortamı ve yasal ve eşitlik, iş, aile vb. İle karakterize olan al- } \\
\text { gisıdır }\end{array}$ \\
\hline $\begin{array}{l}\text { (Türksever ve } \\
\text { Atalik, 2001, s.166) }\end{array}$ & $\begin{array}{l}\text { Nesnel ve öznel boyutlarla birlikte kompleks bir } \\
\text { kavram }\end{array}$ \\
\hline (Fadda, 2003, s.185) & $\begin{array}{l}\text { Bir yaşamı daha iyi hale getiren faktörler. Erişilebilir, sosyal ve } \\
\text { kamusal altyapının sağlandığı bozulma ve kirlilik içermeyen bir } \\
\text { çevre }\end{array}$ \\
\hline (Van Kamp vd., 2003, s.12) & $\begin{array}{l}\text { Yaşam kalitesi; yaşam biçimi, kültür, toplum, güvenlik, doğal } \\
\text { çevre, doğal kaynaklar, yapılı çevre, kamu hizmetleri ve fiziksel } \\
\text { çevre, ekonomi, sağlı ve bireyin karakteri gibi faktörlerin } \\
\text { birleşiminden oluşan bir olgudur }\end{array}$ \\
\hline $\begin{array}{l}\text { Iyi yaşam-yaşam memnuniyeti, refah } \\
\text { (Veenhoven, }\end{array}$ & $\begin{array}{l}\text { Konut ve çevresel kalite memnuniyeti, nesnel kişisel özelliklere } \\
\text { göre nesnel fiziksel ve sosyal çevrenin öznel değerlendirmesi ile } \\
\text { elde edilir. }\end{array}$ \\
\hline $\begin{array}{l}\text { (Kellekci ve } \\
\text { Berköz, 2006, s.175) }\end{array}$ & $\begin{array}{l}\text { Kentsel yaşam kalitesi kavramı altyapı, iletişim, ulaşım gibi fak- } \\
\text { törlerin yanında toplumsal, kültürel, siyasal öğe ve süreçleri } \\
\text { içermektedir }\end{array}$ \\
\hline $\begin{array}{l}\text { (Torlak Evinç ve Yavuzçehre } \\
\text { Savaş, 2008, s.30) }\end{array}$ &
\end{tabular}

(Türkoğlu , Bölen, Baran ve Sadece nesnel koşulların yerleşmelerin kalitesini tam anlamıla Marans, 2008, s.110) ifade etmediği, kalitenin aynı zamanda o birimde yaşayan insanların yaşamlarını yansıtan öznel bir olgu olduğu ifade edilmiştir.

\begin{tabular}{ll}
\hline (Gürel Üçer, & "Yaşam kalitesi; insanların yaşam koşullarından, ilişkilerinden ve \\
2009) & içinde yaşadıkları çevreden duydukları tatmin ve güven de- \\
& recesidir. Bu yönüyle; güvenlik, sağlık, eğitim, kültür, aile, çalışma \\
& koşulları, doğal çevre ve konut gibi yaşam alanlarını tümüne \\
& yönelik olarak duyulan memnuniyet düzeyi, yaşam kalitesini be- \\
& lirlemektedir."
\end{tabular}

\section{Yaşam Kalitesinin Ölçülmesine Yönelik Yaklaşımlar}

Yaşam kalitesinin ölçülmesinde, yaşam kalitesinin ne anlam ifade ettiğinin belirlenmesi ve yaşam kalitesindeki değişikliğin belirlenmesinde kullanılacak göstergelerin seçimi iki önemli unsurdur (Marans 2007, s.335). Farklı ülkelerde ve birçok akademik çalışmada yaşam kalitesinin ölçülmesi için oluşturulmuş farklı göstergeler bulunmaktadır. 
Yaşam kalitesini ölçmek ve izlemek için kullanılacak iki tür gösterge vardır; nesnel ve öznel yaşam kalitesi bileşenlerine atıfta bulunan nesnel göstergeler ve öznel göstergelerdir. Bu göstergeler Tablo 2'de amaçları, bileşenleri ve kullanılan ölçüm araçları olarak kategorize edilmiştir (Evcil Türksever, 2001, s.23). İkisi arasındaki sınır tartışılmakla birlikte nesnel göstergeler olgusal bir durum hakkında bilgi veren ölçümlerdir, sübjektif göstergeler ise bu durumun bir değerlendirmesi hakkındadır (Boelhouwer ve Noll, 2014).

Tablo 2. Yaşam kalitesi göstergeleri (Evcil Türksever, 2001, s.23)

\begin{tabular}{llll}
\hline & ÖZNEL GÖSTERGELER & \multicolumn{2}{l}{ NESNEL GÖSTERGELER } \\
\hline AMAÇ & $\begin{array}{l}\text { Sosyal oluşumları bireyin değer- } \\
\text { lendirmesine bağlı olarak ölçer. }\end{array}$ & $\begin{array}{l}\text { Bireylerin algilamasına bağlı } \\
\text { olmaksızın şartların } \\
\text { değerlendirmesine dayanan } \\
\text { ölçümlerdir. }\end{array}$ \\
\hline BİLEŞENLER & $\begin{array}{l}\text { Yaşamdan hoşnutluk Işinden } \\
\text { hoşnutluk vb. }\end{array}$ & $\begin{array}{l}\text { İşsizlik oranı } \\
\text { Havadaki CO2 miktarı Kişi } \\
\text { başına düşen GSMH } \\
1000 \text { kişiye düşen hekim sayısı }\end{array}$ \\
\hline ÖLÇÜM & Anket, inceleme raporları vb. & Sayım sonuçları, istatistikler vb. \\
ARAÇLARI & & \\
\hline
\end{tabular}

Diener ve Eunkook yaptıkları çalışmada; nesnel göstergeleri belirli bir kültür veya coğrafya birimindeki insanların objektif koşullarını yansıtan toplumsal ölçümler olarak tanımlamışlardır. Bu göstergelerin ayırt edici özelliğinin bireylerin sosyal çevreye bağlı olan öznel algılarının değil, niceliksel istatistiklere dayanması şeklinde söylenebilir. Nesnel göstergelerin güçlü yanı olarak toplumdaki sorunlara işaret edebildiğini belirtmişlerdir. Ancak nesnel göstergelerin zayıf yönünü ise "yanılabilir" olmasıyla tanımlamaktadırlar, mesela bilgi toplamayla ilgili sıkıntılar olduğu zaman elde edilen verilerin doğru gösterge olmadığı düşünülmektedir. Diğer bir zayıf nokta ise; nesnel göstergelerdeki değişkenlerin neye göre seçileceği ve nasıl ağırlıklandırılması gerektiğidir (Diener ve Eunkook, 1997, s.192). Güçlü ve zayıf yönleriyle birlikte nesnel göstergeler 1970 ve 1980 'li yıllarda sosyal politika ve bireylerin yaşam kalitesinin gelişim sürecinin izlenmesi ve karşılaştırma yapılabilmesi için kullanılmıştır (Gürel Üçer, 2009, s.28). Devletlerin kendi kurumlarınca yapmış olduğu araştırma sonuçları ve sayım raporları nesnel göstergeler kullanılarak yapılmaktadır. Ülkemizde Türkiye İstatistik Kurumu, Bakanlıklar ve birçok kurum nesnel göstergeleri kullanarak yaşam kalitesine yönelik araştırmaları yürütmektedir. Yalnızca nesnel göstergelerle kullanılarak yapılan yaşam kalitesi çalışmaları; hane halklarının çeşitli objektif koşulları algılama 
biçimleri ve yorumlama düşüncesini ölçmediği için açıklayıcı olmaktan uzak olması nedeniyle yeterli bulunulmadığı düşünülmektedir (Noll, 2004, s.156).

Öznel göstergeler konusunda öncü çalışmalardan biri olan Campbell'in çalışmasında; yaşam kalitesinde bireylerin algılama, değerlendirme ve memnuniyetlerinin ölçülmesi yaklaşımının da olması gerektiğini öne sürülmüştür. Kişilerin deneyimleri çevreleriyle olan etkileşimlerinden türemektedir ve nesnel göstergelerden farklıdır. Nesnel ölçümlerin yaşam kalitesini ölçmede eksik kalacağı düşüncesi nedeniyle kişiye kendi yaşam olanaklarını nasıl değerlendirdiği sorularak kişisel bir değerlendirme fikrine ulaşılması sağlanmıştır (Campbell, 1981, s.275). Toplumdaki davranış, beklentiler, duygular, istekler ve değer yargılarının izlenmesi gerektiği savunulmuştur (Marans, 2007, s.335). Öznel göstergeler "kişinin yaşam tecrübeleri ve karakteristiğinin dolaylı olmayan raporları" şeklinde adlandırılmaktadır. Tutkular, beklentiler, mutluluk ve hoşnutluk gibi yaşamın pek çok yönüyle ilişkilendirilmektedir. Öznel göstergelerin neler olduğu konusunda uzlaşı sağlanamasa da "hoşnutluk" birçok araştırmacı tarafından en gerekli gösterge olarak nitelendirilmiştir (Evcil Türksever, 2001, s.22).

Yaşam kalitesine yönelik model oluşturma konusunda Türkiye'de de İhan Tekeli yürütücülüğünde bir çalışma yapılmıştır. "Yaşam Kalitesi Göstergeleri" isimli yayında, kavram "yaşamı tüm yönleriyle değerlendirmeyi amaçlayan kapsamı geniş bir kavram" olarak tanımlanmıştır. Bu nedenle yaşamdaki her disiplinin, yaşam pratiği ve faaliyet alanına girdiği belirtilmiştir. Yaşam kalitesi 5 ana başlıkta tanımlanmıştır. Bu başlıklar:

- Yaşam kalitesi kavramının; Hazcı, yararc1, yaşamda bireyin istek sıralamasina, Maslow'cu gereksinmeler kademelenmesine, Sen'ci kapasiteye sahip olmaya dayanan ve Aristocu ereksel açıklamaları

- İnsan Haklarının yaşama geçirilmesi olarak kaliteli yaşam

- Sağlık merkezli yaşam kalitesi kavramı

- Kent merkezli yaşam kalitesi kavramı

- Çevre merkezli yaşam kalitesi kavramı (TÜBA, 2003).

Yaşam memnuniyetini ölçme amaçlı ülkemizde yapılan bir diğer çalışma ise Türkiye İstatistik Kurumu'nun 2003 yılından beri yapmış olduğu "Yaşam Memnuniyeti Araştırması" tır. Bu araştırma kapsamında 4 temel memnuniyet alt başlığı belirlenmiştir. Bunlar:

- Hane halkı yaşam koşulları (hane halkı geliri, yardımlar) 
- Bireysel mutluluk, memnuniyet (mutluluk düzeyi, mutluluk kaynağ1, sağlıktan memnuniyet, çalışma hayatı ve kazanç, kişisel ilişkilerden memnuniyet)

- Kamu hizmetlerinden memnuniyet (sosyal güvenlik hizmetleri, sağlık hizmetleri, eğitim hizmetleri, asayiş hizmetleri, adli hizmetler, kamu hizmetlerinden bilgi edinme, belediye hizmetleri)

- Beklenti, kişisel gelişim ve umut (beklentiler, kişisel gelişim, umut, algilanan refah düzeyi (TÜİK, 2017).

\section{Konut ve Çevresinden memnuniyet}

Yaşam kalitesine yönelik araştırmalara ve ölçüm için kullanılmış olan göstergelere bakıldığında, bireyin yaşam kalitesini belirleyen unsurlardan bir tanesi olarak "konut ve çevresi" kavramının önemli bir parametre olduğu görülmektedir. Barınma koşullarını ve bunların insanların refahı üzerindeki etkilerini ölçmek karmaşık bir iştir. Barınma koşullarını ölçmek için ideal bir gösterge seti hem konutun fiziksel özellikleri hem de konutların bulunduğu alanların daha geniş çevresel özellikleri hakkında bilgi sağlamalıdır. Bu yüzden yaşam kalitesi bağlamında incelerken konut ve çevresi memnuniyetine yönelik önemli kavramsal modeller irdelenecektir.

Öncelikle Francescato ve arkadaşlarının temellerini attıkları model oldukça önemlidir. Dört ana değişken kümesinin memnuniyet ve memnuniyetsizliğe katkı sağladığını belirttikleri çalışmada bu değişkenleri;

- Konut birimi ve fiziksel çevrenin özellikleri

- Konut kullanıcısının demografi yapısı, algı ve davranışları

- Yönetimin algısı, politikaları ve düzenlemeleri

- Proje ve kullanıcıların arasındaki ilişkiler olarak tanımlamışlardır. Bu bağlamda 4 ana kategoride 15 alt parametre belirlenerek alan çalışması gerçekleştirilmişlerdir. Bu parametreler ise; yoğunluk -kalabalık, emniyet- güvenlik, estetik-görünüm, site tesisleri, arkadaşlara erişim, site konumu- topluluğa erişim, bakım, ekonomik maliyet, topluluk duygusu, yönetim politikası, kişisel özgürlük / mahremiyet, topluluk algisı, komşuların algisı, kişilik özellikleri demografik özelliklerdir (Francescato vd., 1974, s.287)

Konut memnuniyeti açısından bir diğer önemli model ise Galster ve Hesser'in çeşitli araştırmacıların modelleri sonucunda geliştirmiş olduklarl; temelinde memnuniyetin yerleşimin ve konutun nesnel "bağlamsal" özelliklerinden ve yanıtlayan kişinin nesnel "bütüncül" özelliklerinden etkilendiğini 
ileri sürmektedir. Bu bağlamda kurgulanan 3 bağımsız değişken ve bu değişkenlerin alt parametreleri çalışmanın ana kurgusunu oluşturmuştur. Bu değişkenler;

- Kullanıcının demografik özellikleri: yaş, ırk, çocuk sayısı, gelir düzeyi, eğitim durumu vb.

- Yerleşim özellikleri: konutun ortalama değeri, son beş yıl içinde oturan kullanıcı oranı, kullanılmaz durumda olan konutların oranı, kullanılmayan alanların toplam alana oran,

- Konutun fiziksel özellikleri: sihhi tesisat, ısıtma, iç-dış koşullar, oda sayısı, banyo, avlu alanı vb. parametreleri kapsamaktadır (Galster ve Hesser, 1981, s. 745).

Marans ve Sprecklemeyer'in (1981) kavramsal modelleri fiziksel çevrenin objektif özellikleriyle, konut ve çevresinden memnuniyetin davranışla ilgili ilişkisini tanımlamaktadır. Konut memnuniyetinin çevresel özelliklerden etkilendiği gibi kişilerin davranış özelliklerinden de etkilendiğini ortaya koymaktadır. Şekil 1'de yer alan bu model sonrasında gelecek birçok araştırmaya da fikir vermiş ve ilerleyen yıllarda geliştirilmiştir.

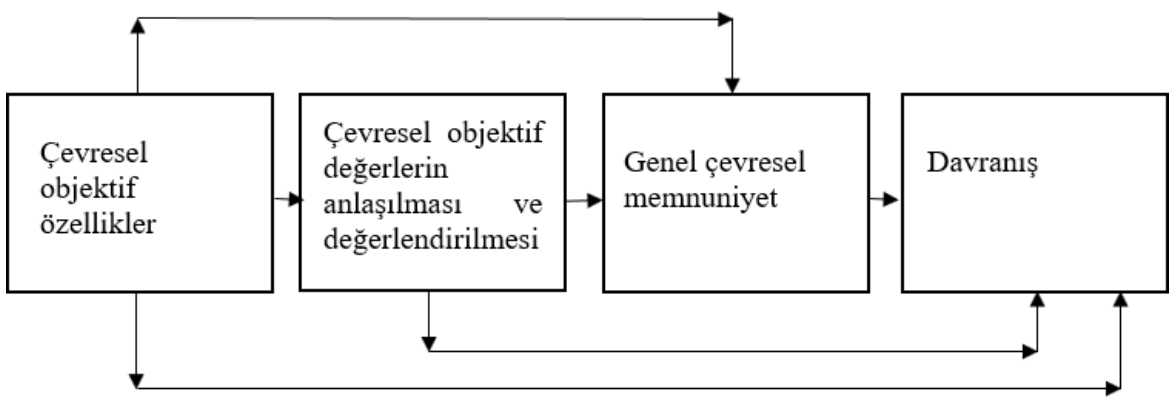

Şekil 1. Marans konut memnuniyeti modeli (Marans ve Spreckelmeyer, 1981)

Enosh ve ark.larının geliştirmiş oldukları ve İsrail'de 5 mahallede 400 kişiye uygulamış oldukları model de konut memnuniyeti açısından önemlidir. Öncelikle modelin kavramsal altyapısında; kişinin yaşam kalitesinin belirli nitelikte olan ihtiyaçlarının ne ölçüde karşılandığı düşüncesi yatmaktadır. Bu bağlamda mahremiyet, rahatlık, güvenlik, keyif ve saygı gibi kavramlar önemli bir etkendir. Özellikle bu model insanlar arasındaki farkın, olanakları varlığı ya da yokluğuyla değil, bu olanaklara göreceli önemde verdikleri tepkiyle yaşamdan duyulan memnuniyetin farklılaştığını öne sürmesi açısından önemlidir. Model Marans'ı destekler nitelikte, özellikle yerleşim memnuni- 
yetinin ölçülmesinde nesnel ölçümlerin kullanılmasının yanı sıra aynı zamanda kişisel özelliklerle öznel ölçümlerin de dahil olması gerekliliğine vurgu yapmaktadır. Bu anlamda:

- Yerleşim özelliklerini: nüfus bileşimi, konut birimlerinin yoğunluğu, hizmetlere yakınlık, açık alan miktarı, parklar, oyun alanları

- Kişinin demografik yapısını: eğitim, yaş, etnik köken, medeni durum, meslek, gelir, ikamet süresi, konut birimi mülkiyeti gibi parametrelerle tanımlamıştır.

Ayrıca yerleşim özelliklerinin öznel değerlendirmesi için:

- Komşular, ağaçlar, parklar, hizmetler gibi kaynakların değerlendirilmesi

- Uygunluk, güzellik ve estetik, temizlik, sessizlik, güvenlik gibi parametrelerin değerlendirilmesi şeklinde belirlenmiştir (Enosh vd., 1984, s.460)

Weidemann ve Anderson, Marans ve Sprecklemeyer' in modelini geliştirerek "ilişkilendirilmiş model" ismini verdikleri bir kavramsal model ortaya koymuşlardır. Bu modelde kişilik özellikleri ve buna bağlı olarak verilen cevapların; çevreyle ilgili pozitif ve negatif davranış biçimlerini yansıttığı öngörülmektedir. Şekil 2'de yer alan modelde herhangi bir değişken bir diğer değişkeni etkileyebilmektedir. Aynı zamanda objektif çevresel özelliklerin fiziksel (site planı, yoğunluk), sosyal (konut kullanıcıları arasındaki ilişkiler, sosyal organizasyonlar) ve kişinin demografik özelliklerinin ortaya konmasıdır.

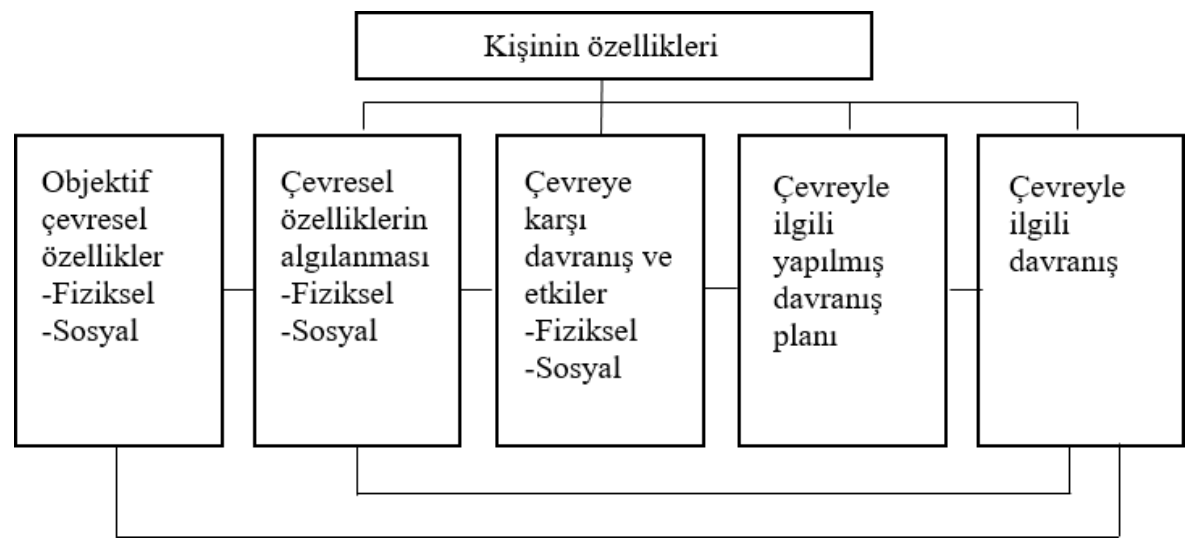

Şekil 2. Weidemann konut memnuniyeti modeli (Weidemann ve Anderson, 1985) 
Weidemann ve ark.ları, yine aynı çalışmada modellerini detaylı bir biçimde tanımlamışlardır. Bu tanımlamada: konut ve çevresini bir kalite göstergesi olarak kullanılmış olup, çeşitli ölçekler kullanılmıştır. Bunlar: oda, konut, konut ve çevresi, mahalle, bölge ve toplumsal çevredir. Bu farklı ölçeklerin her biri için nesnel çevresel değişkenler, inanç ve memnuniyet derecesi, sosyal ve fiziksel ilişkilerin varlığıyla model oluşturulmaktadır. (Weidemann vd., 1985, s.170)

Amerigo ve Aragones' in geliştirmiş oldukları konut memnuniyeti modeli birçok çalışma için referans kaynağı olmuştur. Bu model kendi deyiş̧iyle bir konut memnuniyet modelinden daha fazlası olup, birey ile yaşadığı ortam arasındaki dinamik etkileşimi; bilişsel, duyusal ve davranışsal farklı süreçleri analiz ederek kurmayı amaçlamaktadır. Bu bağlamda Şekil 3’ de görüldüğg̈ üzere, konut ve çevresinin nesnel özellikleri birey tarafından değerlendirildikten sonra öznel bir hale gelir ve belirli bir memnuniyet düzeyi oluşmaktadır. Bu noktada öznel değerlendirmeler bireyin "kişisel özellikler" inden etkilenmektedir. Kişisel özellikler; kullanıcının sosyo-demografik özelliklerini ve kendi "ideal yerleşim kalitesi modelini" ortaya koymaktadır. Bu değerlendirmenin sonucu, yani mesken tatmini, bireyin yaşadığı çevreye karşı deneyimlediği ve o çevreyle uyumu sürdürmek veya arttırmak için belirli şekillerde davranmasina neden olacak olumlu bir duygusal durumdur (Amerigo ve Aragones, 1997, s.49)

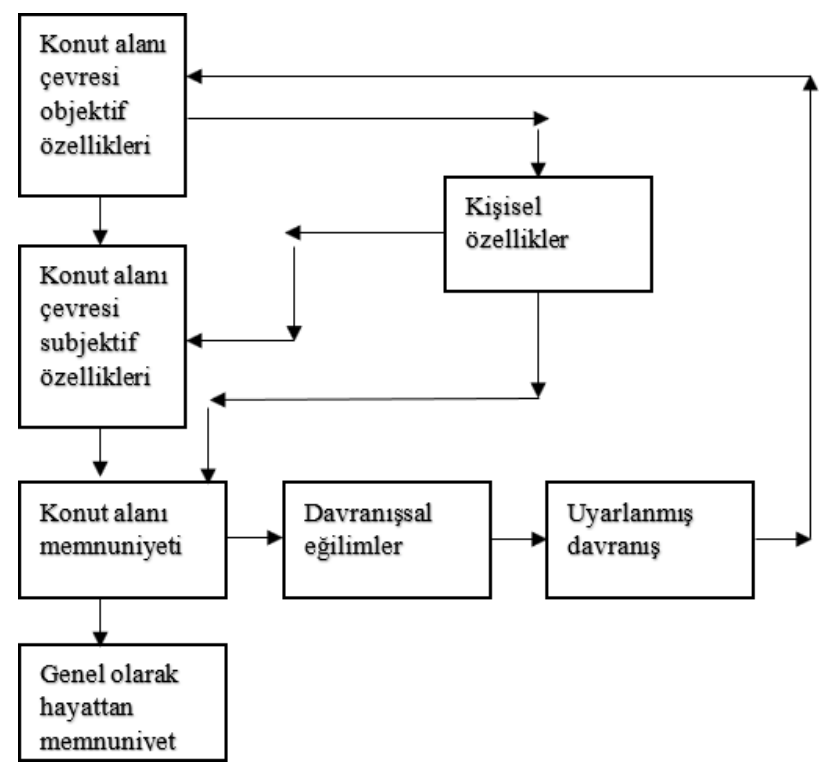

Şekil 3. Amerigo ve Aragones konut memnuniyeti modeli (Amerigo ve Aragones, 1997) 
Je ve ark.ları çalışmalarında; altyapı (ekipmanlar, yaşama uygunluk, sağlık, hoşnutluk, güvenlik), görsel faktörler (manzara, form, görsel denge), alan kullanımı (sirkülasyon, alan fonksiyonları, alan verimliliği), sosyal çevre (çevre, sosyal ilişkiler), yönetim (yönetim, güvenlik, ekonomik değer) olmak üzere 5 faktör belirlemişlerdir. Çalışmada alan kullanımı faktörü memnuniyete en çok etki eden faktör olmuştur. Plan kullanımı, binaların birbirine olan konumu önemli parametrelerdendir (Je vd., 2007, s. 900)

Ülkemizde ise Türkoğlu, İstanbul'da konut kullanıcı memnuniyetini ölçmek için 480 kullanıcının katılımıyla yaptığı çalışmada; konutun büyüklüğü ve fiziksel koşulları, şehir merkezine, iş yerine, hastaneye, alışveriş ve belediye hizmetlerine erişim, sosyal, eğlence ve eğitim hizmetlerinin bulunabilirliği ve bakımı, sosyal ve fiziksel çevre sorunları, konutun iklimsel kontrolü ve komşularla memnuniyet olmak üzere 6 faktör grubu belirlemiştir (Türkoğlu, 1997, s.60).

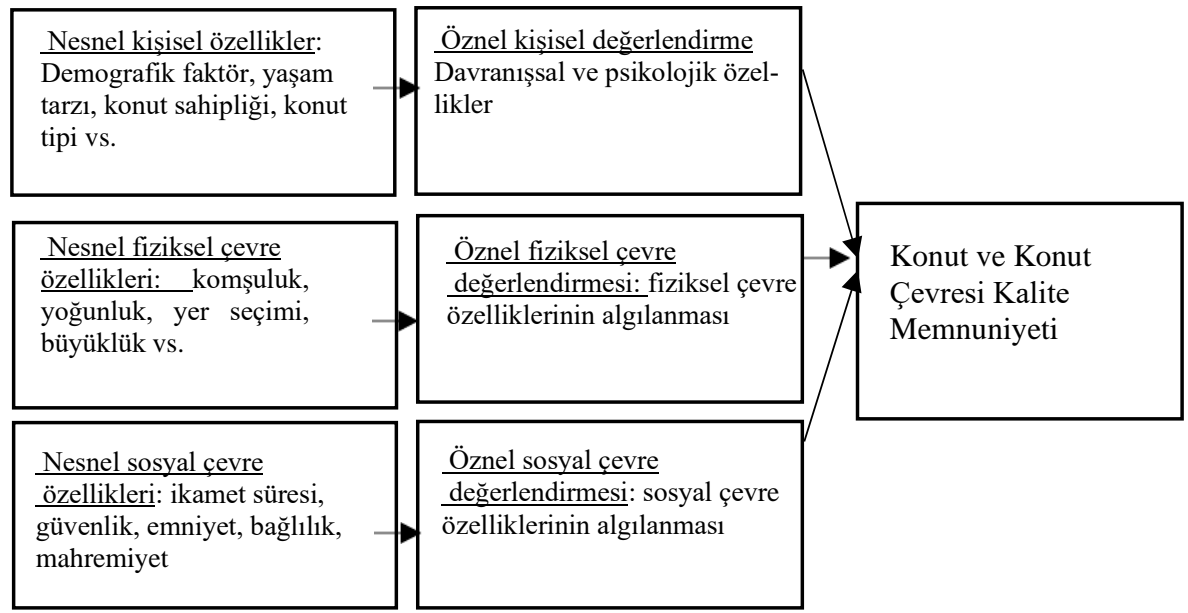

Şekil 4. Kellekci ve Berköz'ün konut memnuniyeti modeli (Kellekci ve Berköz,2006)

Kellekci ve Berköz, İstanbul'da yaptıkları alan çalışmasında 401 kullanıcıya anket uygulamışlardır. Şekil 4'te görüldüğü üzere; kullanıcıların konut ve çevresel kalite memnuniyetini geniş bir perspektifte değerlendirerek; nesnel kişisel özellikler, fiziksel çevre özellikleri ve sosyal çevre özelliklerini kişisel algılama sonunda elde edilen öznel kişisel değerlendirmeler sonucunda kavramsal bir model oluşturulmuştur (Kellekci ve Berköz, 2006, s.171).

Gür; Bursa toplu konutlarda yapılan kullanıcı memnuniyetinin ölçülmesine yönelik çalışmasında erişilebilirlik-ulaşım, çevresel faktörler, sosyal do- 
natılar ve açık alanlar, komşuluk ilişkileri, konutun fiziksel özellikleri, güvenlik ve konutun iklimsel kontrolü faktörlerini oluşturmuştur. 364 kişilik örneklem grubuyla yapılan çalışmada; konut ve çevresinden memnuniyeti sosyal donatıların çeşitliliği ve kalitesinin etkilediği, erişilebilirlik ve konutun fiziksel özelliklerinin memnuniyetin oluşmasında önemli bir etken olduğu sonucu çıkmıştır (Gür, 2009, s.179)

\section{Sonuç}

Yaşam kalitesi birçok disiplin tarafından yıllardır tartışılan ve tanımlanan bir kavram olarak güncelliğini korumaktadır. Bu noktada birçok disiplin yaşam kalitesine kendi çerçevesinden bir perspektif sunmaktadır. Kentsel tasarım ve mimarlık disiplinleri bağlamında bakıldığında yaşam kalitesinin üst ölçekli ve daha küçük ölçekli olmak üzere değerlendirildiği görülmektedir. Bu çalışmada yer alan "konut ve konut çevresi" kavramı ise mimarlık disiplini bağlamında yaşam kalitesine doğrudan etki eden bir yaklaşımla değerlendirilmiştir. Bu noktada bireyin yaşamdaki en çok vaktinin geçtiği ve barınma gereksinimi temel alınarak birçok ihtiyacına mekânsal olarak karşılık veren konut biriminde kalite konusu ön plana çıkmaktadır. Bu bağlamda yalnızca fiziksel özelliklerden oluşacak kalitenin yanı sıra sosyal, kültürel ve mekân kalitesi için gerekli kalite parametrelerinin de konut ve çevresi kalitesinde pay sahibi olduğu düşünülmektedir Yapılan literatür araştırması göstermektedir ki; konut ve konut çevresinden memnuniyetle ilgili birçok farklı yaklaşım ve model görülmektedir. Bu da konuya dar bir perspektiften bakılamayacağını, konunun derinliklerine inildikçe çok farklı parametrelerin de devreye girdiğini göstermektedir. Kullanıcıların zevk aldıkları, mutlu oldukları konut alanlarında yaşamaları, ruhsal olarak tatminlerini artırmakta ve bu durum yaşam kalitelerinin artmasına neden olmaktadır.

Literatürde tartışlan konut ve çevresine yönelik parametreler; site görünümü, yönetim, bakım, güvenlik, komşuların homojenliği, konut içindeki alanların kalitesi, konut çevresindeki açık alanlardaki imkânlar, konutun büyüklüğü ve fiziksel koşulları, şehir merkezine, iş yerine, hastaneye, alışveriş ve belediye hizmetlerine erişim, sosyal, eğlence ve eğitim hizmetlerinin bulunabilirliği ve bakımı, sosyal ve fiziksel çevre sorunları, konutun iklimsel kontrolüdür. Aynı zamanda kişisel özelliklerin yaşam kalitesindeki öznel değerlendirmeleri etkilediği gözlemlenmiştir. Ayrıca mekân kalitesine etki eden düzen, kimlik, güvenlik, çeşitlilik gibi parametrelerin de konut ve çevresi memnuniyetini etkilediği görülmektedir. 
Literatür kapsamında incelenen çalışmalar değerlendirildiğinde yaşam kalitesi temel alınarak yapılan salt nesnel ölçümlerin yeterli olmayacağı görülmüştür. Günümüzde yalnızca nesnel, yalnızca öznel ve hem nesnel hem de öznel göstergelerin kullanıldığı çalışmalar bulunmaktadır. Bu bağlamda her iki gösterge türünün bir arada kullanılmasıyla elde edilen daha objektif sonuçlar ortaya koymaktadır.

Yaş, cinsiyet, gelir durumu, medeni durum, iş durumu gibi özellikler bireylerin yaşam memnuniyetlerini ve karar süreçlerini etkileyen önemli etkenlerdir. Bu nedenle birçok yaşam kalitesi modelini destekler nitelikte; ölçümlerde öznel görüşlerin kullanılması ve yere özgü bölgesel ölçümler yapılması son derece önemlidir. Kullanıcıların değişen gereksinimlerini karşılayacak şekilde yaşam kalitesini artıran bu değerlendirmelerin konut ve çevresinin tasarımının geliştirilmesinde de önemlidir. Bu doğrultuda buradan elde edilen bilgilerle yaşam kalitesinin önemli bir unsuru olan fiziki yaşam alanının oluşturulmasında teknik değerlerle birlikte muhtemel kullanıcıların görüşlerinden ya da olası isteklerinden de faydalanılmalıdır.

$\mathrm{Bu}$ bağlamda çalışmada yer alan modeller ve değerlendirmelerin; karar vericiler için bir çözüm önerisi niteliğinde olması umulmaktadır. Kent ve konut alanlarının planlaması için gerekli olan tasarım girdileri ve karar mekanizmaları için çalışmada yer alan modeller ve sonuçların yol gösterici nitelikte olacağı öngörülmektedir. Bu noktada bu veriler doğrultusunda yapılan ve yapılacak olan nitel araştırmalarla konut ve çevresinin yaşam kalitesi üzerine etkisinin geliştirileceği düşünülmektedir. 


\title{
Extended Abstract
}

\section{Evaluation of Approaches to the Concept of Housing and Its Environment in the Context of Quality of Life}

\author{
Betül Hatipoğlu Şahin 5 \\ ORCID: 000-0002-0516-7120
}

\author{
Ayşegül Terecí \\ ORCID: 0000-0001-5989-9565
}

Although the origin of the concept of quality of life that evaluates people and the environment they live in, dates back to ancient times, research reveals that the concept does not have an agreed and an explicit definition upon. Especially due to its versatile and complex structure; It is seen that in many fields such as social sciences, engineering, natural sciences, and health sciences it has become research subject. At this point, each discipline has redefined the concept within its own framework. The concept, which has been recorded more than 100 definitions in different sources, is expressed as life satisfaction, general welfare, human development, complacency in many sources. Quality of life studies aims to investigate the causes of the factors that make up the sense of well-being of individuals and to reveal their effects, to provide information on the social and spatial distribution of satisfaction and dissatisfaction, to establish effective policies based on the results of the research and to follow the spatial effects of these policies, to determine the changing trends by comparing them with subsequent measurements. The approaches of researchers such as Campbell (1981), Pacione (1986), Marans (2003), Van Kamp (2003), Bonaiuto (2003), Veenhoven (2004) to quality of life studies have led to the emergence of different models. Especially, the relationship of the individual with the place and environment has formed the main point of the research.

Quality of life research at urban scale; it has been effective in making decisions about location and migration in cities. At this point, the discipline of

\footnotetext{
${ }^{5}$ Lecturer., KTO Karatay University, E-mail: betulhatip@gmail.com

${ }^{6}$ Assist. Prof. Dr., KTO Karatay University, E-mail: aysegul.tereci@karatay.edu.tr

idealkent @ Kent Araştırmaları Dergisi (Journal of Urban Studies)

http://idealkentdergisi.com

Geliş Tarihi Received Date: 22.12.2020 Kabul Tarihi Accepted Date: 12.09.2021
} 
architecture draws a frame to the quality of life in a spatial context. According to the study conducted by Tekeli et al. (2010), there are different individualcentered, individual satisfaction-centered and environmental-centered evaluations in the perspectives here. Apart from definitions, it is seen that different indicators are used for quality of life measures, especially in different countries and in many academic studies. At this point, it has been revealed in the quality of life studies that the quality of life of a person depends on two basic factors, namely social environment, and physical environment. Social environment factor is evaluated with family, friends, and spouse satisfaction; The physical environment factor is evaluated together with components such as urban life quality, housing satisfaction, neighborhood, city, region, or country characteristics.

In the literature research, it was seen the housing and environmental satisfaction is an indicator that directly affects the quality of life. The concept of housing and environmental has become one of the fundamental categories, especially in the "life satisfaction" research conducted by countries for their own citizens. The concept of housing, the production of the house, the experiences in the house, the factors effected and affected by the house, the effects of historical, social, and economic factors on the shaping of the house have been the topics where architectural discipline is discussed, and continuous production of knowledge is made. Housing generally defined as the home of the person, the place where who live, shelter of daily life, status in the socioeconomic structure, symbol, and many psychological and social characteristics, where people have emotional relations with the environment, they live in. Housing is a cognitive place as well as a physical place that also includes neighborhood and social environment together. Especially the housing and environmental, where the individual spends a significant part of individual's life, has become an important component of the quality of life due to this feature. In the literature research conducted within the scope of the study; the models aiming to measure the satisfaction levels and life quality of the users for the house and its surroundings were examined. Especially the studies aiming to create a model reveals the importance of the subjective judgements of the individual in the evaluation of the objective and subjective qualities of the housing area. In many models examined in this context; housing and environmental satisfaction has been considered as a whole and the data obtained as a result of personal perception were effective in the formation of a conceptual model. At this point, many sub-parameters specified in different models were determined in the measurement of housing and environmental 
satisfaction. These parameters are generally, site view, management, maintenance, security, homogeneity of neighbors, quality of spaces within the residence, opportunities in open spaces, size and physical conditions, access to the city center, workplace, hospital, shopping and municipal services, availability of social, entertainment and educational services and maintenance, social and physical environmental problems, climatic control of the housing. In the scope of the study, it's aimed to examine and discuss models and the subparameters connected to these models in the literature.

\section{Kaynakça/References}

Amerigo, M. ve Aragones, J. (1997). A theoretical and methodological approach to the study of residential satisfaction. Journal of Environmental Psychology, 47-57.

Becker, M. ve Diamond, R. (1997). New developments in quality of life measurement in schizophrenia. H. \&. H. Katschnig içinde, Quality Of Life İn Mental Disorders (s. 119133). New York: Wiley.

Boarini, R., Comola, M., Keulenaer, F., Robert, M., \& Conal , S. (2010). The determinants of well-being in OECD countries. Paris: OECD Statistics Directorate, 6-35.

Boelhouwer, J. ve Noll, H.-H. (2014). Objective quality of life. A. Michalos içinde, Encyclopedia of Quality of Life and Well-Being Research. Dordrecht: Springer.

Bourdieu, P. (1984). Distinction: a social critique of the judgement of taste. London \& New York: Routledge.

Campbell , A. (1981). The sense of well-being in America: tecent patterns and trends. Social Forces, 263-289.

Coombes, P. ve Cook, N. (1998). QOL as a focus for strategies and benchmarking for cities. The First International Conference On Qol In Cities: Issues And Perspective. Singapore.

Dalkey, N. ve Rourke, D. (1972). The Delphi procedure and rating quality of life factors. U. S. United States. Environmental Protection Agency Environmental Studies Division içinde, The Quality of Life Concept: A Potential New Tool for Decision-makers, Volume 1 (s. 210-218). United States. Environmental Protection Agency.

De Hollander, A.E.M; RVIM. (2000). National Institute for public health and the environment in the Netherlands. 5e Nationale Milieu Verkenningen.

Diener, E. ve Eunkook, S. (1997). Measuring QOL economic,social, and subjective indicator. Social Indicators Research, 189-216.

Dissart, J. ve Deller, S. (2000). Quality of life in the planning literature. Journal Of Planning Literature, 135-161.

Enosh, N., Leslau , A., Shacham, J. (1984). Residential quality assessment: a conceptual model and empirical test. Social Indicators Research volume, 453-476.

Evcil Türksever (2001). Türkiye'de büyükşehir alanlarında yaşam kalitesinin değerlendirilmesine yönelik bir yöntem denemesi. Doktora Tezi. İstanbul: ITÜ, FBE. 
Fadda, G. (2003). Urban sustainability, quality of life and gender. In City And Gender International Discourse On Gender, Urbanism And Architecture (s. 177-190). Opladen, Germany: Leske + Budrich.

Francescato, G., Weidemann, S., Anderson, J., Chenoweth, R. (1974). Evaluating residents' satisfaction in housing for low and moderate income families: a multimethod approach. Illinois: Housing Research and Development University of Illinois, 285-295.

Galster, G. ve Hesser, G. (1981). Residential satisfaction: compositional and contextual correlates. Environment and Behavior, 735-758.

Gökmen, L. (2016). Konutta proje ligi. Ekonomist:http://www.ekonomist.com.tr/kapakkonusu/konutta-proje-ligi.html adresinden alındı

Gür, M. (2009). Kullanıcıların konut ve çevresel kalite memnuniyetinin belirleyicileri: istanbul metropoliten alan örneği. Yüksek Lisans Tezi. Bursa: Uludağ Üniversitesi / Fen Bilimleri Enstitüsü.

Gürel Üçer, Z. (2009). Kentsel yaşam kalitesinin belediye hizmetleri kapsamında belirlenmesine ve geliştirilmesine yönelik bir yaklaşım : orta ölçekli kent örnekleri. Doktora Tezi, Gazi Üniversitesi Fen Bilimleri Enstitüsü.

Harland, D. (1972). Social indicators: toward the measurement of quality of life. Ottawa: Regional Economic Expansion .

Je, H., Lee, J., Cheong, S., Shin, S.-W. (2007). A study on residential quality index of super high-rise apartment housing through survey with experts. Proceedings Of The International Conference On Sustainable Building Asia, Seul, 899-904.

Jenkinson, C. (2020,). Quality of life. Encyclopædia Britannica: https://www.britannica.com/topic/quality-of-life adresinden alındı

Kellekci, Ö. ve Berköz, L. (2006). Konut ve çevresel kalite memnuniyetini yükselten faktörler. İtü Dergisi/A Mimarlik, Planlama, Tasarım, 167-178.

Lansing, J. ve Marans, R. (1969). Evaluation of neighbourhood quality. Journal Of The American Planning Association, 195-199.

Liu, B. ve Hsieh, C. (1986). Effects of educational expenditures on regional inequality in the social QOL. American Journal Of Economics And Sociology, 45(2), 131-144.

Marans, R. W. (2007). Kentsel yaşam kalitesinin ölçülmesi. Mimarlık Dergisi, 335.

Marans, R., \& Spreckelmeyer, K. (1981). Evaluating Built Environments: A Behavioral Approach. Michigan: Survey Research Center, Institute for Social Research, University of Michigan.

Marsella, A., Levi, L., Ekblad, S. (1993). The importance of including quality of life indices in international social and economic development activities. Applied And Preventive Psychology, 55-67.

Masilimani, R. (2007). Peoples perception of quality of life concept in urban development process: Case Chennai. Anna Üniversitesi, Mimarlk ve Planlama Fakültesi, Chennai, 1-246.

Murdie, R., Rhyne, D., Bates, J. (1992). Modeling quality of life indicators in Canada: A feasibility analysis. Toronto: York University, Institute for Social Research, 14-59. 
Murray, J. (1900). Murray's hand-book constantinople Brusa, and the Throad. London: John Murray.

Noll, H.-H. (2004). Social indicators and quality of life research: background, achievements and current trends. N. Genov içinde, Advances in Sociological Knowledge. Wiesbaden: VS Verlag für Sozialwissenschaften, 151-181.

Perloff, H. (1969). The quality of the urban environment. Washington D.C: John Hopkins Press for Resorces For The Future.

Prutkin, J. ve Feinstein, A. (2002). A history of quality of life measurements. Yale Medicine Thesis Digital

Library:

https://elischolar.library.yale.edu/cgi/viewcontent.cgi?article=1423\&context=ymtdl adresinden alındı, 1-25

Rice, R., Frone , M., McFarlin, D. (1992). Work-Nonwork conflict and the perceived quality of life. Journal of Organizational Behavior, 155-168.

Roitman, S. (2010). Gated communities: definitions, causes and consequences. Urban Design and Planning, 163(1), 31-38.

Rojek, C. (2000). Indexing, dragging and the social construction of tourist sights. C. R. Urry içinde, Touring Cultures. Transformation of Travel and Theory, New York: Routledge, 52-74.

Schalock, R. (2004). Quality of life: What we know and do not know. Journal of Intellectual Disability Research, 48 (3), 203-216.

Shookner, M. (1997). A quality of life index for Ontario. Conference On The State Of Living Standards And The Quality Of Life In Canada. Ontario - Canada: Ontario Social Development Council, 1-25.

Streimikiene, D. (2015). Quality of life and housing. International Journal of Information and Education Technology, (5/2)140-145.

Torlak Evinç, S. ve Yavuzçehre Savaş, P. (2008). Denizli kent yoksullarının yaşam kalitesi üzerine bir inceleme. Çağdaş Yerel Yönetimler, 23-44.

TÜBA (2003). Yaşam kalitesi göstergeleri, Türkiye için bir veri sistemi önerisi. Ankara: Türkiye Bilimler Akademisi.

TÜIKK. (2017). Yaşam Memnuniyeti Araştırması 2003-2017. TÜIK yayınlar: https://biruni.tuik.gov.tr/yayin/views/visitorPages/index.zul adresinden alınd1

Türkoğlu, H., Bölen, F., Baran, P., Marans, R. (2008). İstanbul'da yaşam kalitesinin ölçülmesi. İtü Dergisi A - Mimarlık, Planlama, Tasarım, 103-113.

Türkoğlu, H. (1997). Residents' satisfaction of housing environments: The Case of Istanbul, Turkey. Landscape and Urban Planning, 55-67.

Türksever , A. ve Atalik, G. (2001). Possibilities and limitations for the measurement of the quality of life in urban areas. Social Indicators Research, 163-187.

Van Kamp, I., Kees, L., Gooitske , M., Augustinus , D. (2003). Urban environmental quality and human well-being towards a conceptual framework and demarcation of concepts; a literature study. Landscape And Urban Planning, 5-18.

Veenhoven, R. (2004). Quality-of-life research, 1-23. 
Weidemann, S. ve Anderson, J. (1985). A conceptual framework for residential satisfaction. I. Altman, \& C. Werner içinde, Home Environments. Human Behavior and Environment (Advances in Theory and Research), Baston: Springer, 153-182.

WHO. (1995). The world health organization quality of life assessment. Soc. Sci. Med.

Wish, N. (1986). Are we really measuring quality of life. American Journal Of Economics And Sociology, 343-358. 